\title{
Pan African Sanctuary Alliance: securing a future for the African great apes
}

\author{
R. STOKES ${ }^{1}$, G. TULLY ${ }^{1, *}$ \& A. G. ROSATI ${ }^{2}$ \\ ${ }^{1}$ Pan African Sanctuary Alliance, Portland, Oregon 97219, USA, and ${ }^{2}$ Department of \\ Psychology, The University of Michigan, Ann Arbor, Michigan 48109, USA \\ E-mail: gregg@pasaprimates.org
}

The Pan African Sanctuary Alliance (PASA) is the unified voice of primate rescue and rehabilitation projects in Africa, and includes 23 member organizations in 13 countries. PASA improves animal welfare by regularly evaluating these sanctuaries to ensure that they operate at a high standard of care, building the capacity of sanctuary staff and providing crisis support to mitigate emergencies. Moreover, PASA works with its member organizations to raise awareness globally about wildlife issues and to conduct other large-scale conservation projects. In these endeavours, PASA benefits greatly from the local experience and connections of its member organizations. Finally, nearly all PASAmember sanctuaries host researchers, thereby contributing to our knowledge of the great apes and other African primates. Much of PASA's work is made possible by support from zoos around the world. A brief precis of the current work carried out by PASA and its member organizations is given, along with descriptions of conservation programmes that are planned for the future.

Key-words: Africa; chimpanzees; conservation; gorillas; great apes; primates; research; welfare.

\section{HISTORY OF THE PAN AFRICAN SANCTUARY ALLIANCE (PASA)}

Pan African Sanctuary Alliance (PASA), the largest association of wildlife centres in Africa, includes 23 organizations that collectively care for more than 3000 rescued primates (Fig. 1; Table 1). Prior to PASA's formation, these wildlife centres had similar goals and were facing similar challenges, but largely did not communicate with one another. In 2000, conservationists, primatologists and senior zoo personnel arranged a meeting in Uganda to bring the wildlife centres together for the first time. The directors of the organizations agreed there was a need for improved ongoing communication and, as a result, PASA was formed. Although PASA's headquarters is now in Portland, Oregon, USA, and it is registered as a '501(c)(3) nonprofit organization' in the United States, it was created by the African wildlife centres. PASAmember institutions work to secure a future for all African primates and their habitat. In this article, the authors focus on how this unique collaboration of African sanctuaries, communities, governments and global experts impacts the welfare and conservation of great apes.

Despite working in extraordinarily challenging conditions, members of the Alliance are making significant strides in great ape welfare and conservation. They give lifelong care to primates orphaned by the bushmeat trade and confiscated from the illicit pet trade, collaborate with lawenforcement agencies to stop the hunting and trafficking of threatened species, defend critical habitat from exploitation, and conduct community development and education programmes, reaching more than 500000 people across Africa each year. Additionally, PASA-member wildlife centres provide employment for nearly 700 African people and inject millions of dollars into

*Correspondence: Gregg Tully, Pan African Sanctuary Alliance, Portland, Oregon 97219, USA. E-mail: gregg@ pasaprimates.org. Twitter: @pasaprimates 


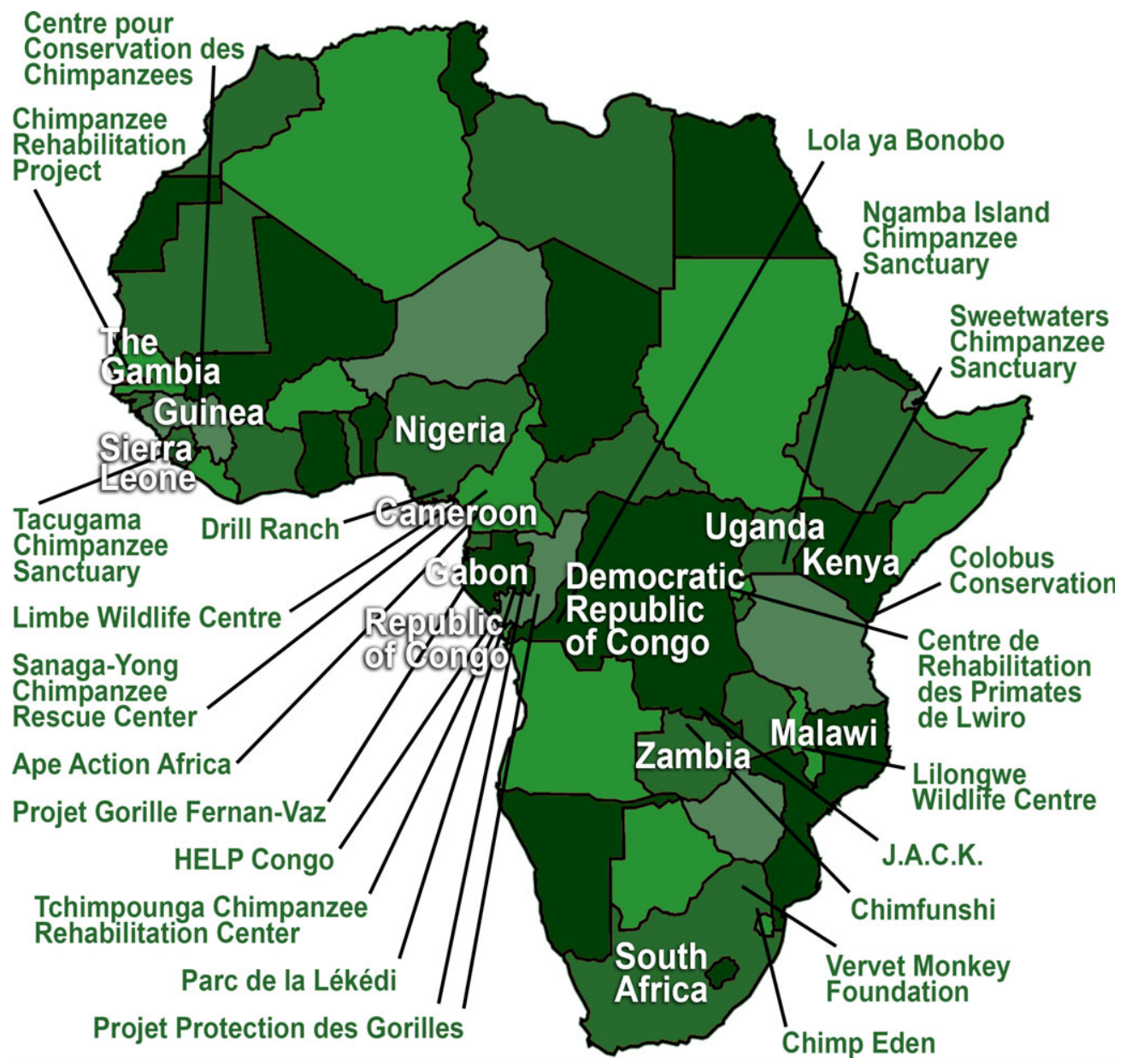

Fig. 1. Map of Pan African Sanctuary Alliance member sanctuaries. Pan African Sanctuary Alliance, 2017.

local economies. Ferrie et al. (2014) provide details on the work carried out by PASA, although it has now surpassed many of the achievements described in that publication.

\section{PASA STRENGTHENS ITS MEMBER SANCTUARIES}

PASA's unique evaluation and accreditation process brings credibility to the wildlife centres, and PASA membership gives them access to a global network of advisors, including experts from zoos around the world, veterinarians, conservationists, primatologists and educators. Moreover, many of PASA's programmes are aimed at ensuring the success of its member organizations. A series of published manuals are freely available on PASA's website (https://www.pasaprimates.org/reportsmanuals), providing information about sanctuary standards and best practices, primate veterinary health, and strategies and methods for conservation-education programmes in Africa. These are widely used throughout the African primate sanctuary community. PASA's annual reports and 




Table 1. The Pan African Sanctuary Alliance (PASA) is an association of 23 wildlife centres in $\mathbf{1 3}$ countries working to secure a future for primates in Africa and their habitats.

reports on recent conferences are also available.

\section{Strategic Development Conference}

PASA holds an annual Strategic Development Conference for the directors of its member wildlife centres. This conference provides directors with an opportunity to share ideas and learn from each other, and to discuss how PASA can most effectively support their work (Plate 1). PASA also invites sanctuary directors, leaders of zoos and consultants to give presentations and participate in panel discussions on diverse topics, including fundraising, disease prevention, enclosure construction and strategic planning. This helps the sanctuaries to improve their primate care, become more sustainable and achieve their missions. In 2017, for the first time, the Strategic Development Conference was combined with a Conservation Education and Outreach Workshop for the coordinators of education programmes at the wildlife centres (PASA, 2017). The conference and workshop were attended by 53 people, including 17 leaders and 14 education professionals from PASAmember organizations, four members of PASA's Board of Directors, and others committed to the conservation and protection of Africa's primates (PASA, 2017). In previous years, members of the European Association of Zoos and Aquaria (EAZA) participated regularly in the conference and offered valuable insights on areas such as organizational management, networking and writing grants. Several chapters of the American Association of Zoo Keepers (AAZK) support PASA and its members, particularly by sponsoring wildlife-centre directors to attend the annual PASA conference.

\section{Primate Care Training Program}

Many alliance members lack the funding and connections necessary to provide staff with advanced training by skilled instructors. In 2017, PASA responded to this problem by launching a Primate Care Training Program aimed at engendering significant, long-term improvements in the welfare of thousands of great apes and monkeys. PASA identifies highly qualified instructors who are employed by zoos or have managed primate care and have abundant experience in training African primate caregivers, and matches them with PASAmember sanctuaries whose training needs meet their specialties. PASA then arranges for the instructors to spend weeks or 


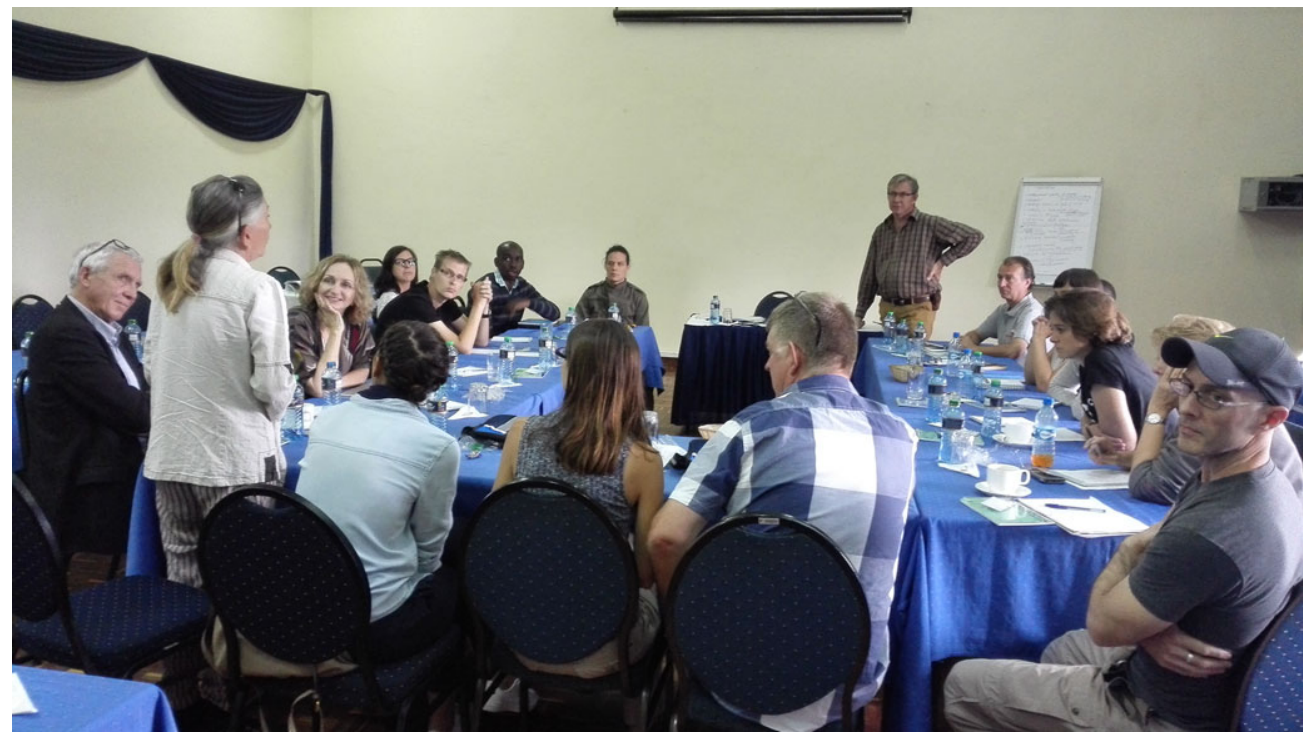

Plate 1. Directors of sanctuaries and wildlife centres that are members of the Pan African Sanctuary Alliance have a meeting at The Strategic Development Conference in Nairobi, Kenya, in December 2015. Pan African Sanctuary Alliance, 2017.

months at the sanctuaries to train all the animal-care staff. The specific topics covered, duration of the training and teaching methods are customized for the needs and resources of each sanctuary. Since the start of the Program in early 2017, more than 300 staff who work directly with animals have received comprehensive training. The instructors, who have often gained their own experience by working in zoos, teach animal-care staff to follow internationally recognized best-practice guidelines and work to high standards. In addition to training animal-care staff directly, the instructors will teach the management how to educate new staff. Printed materials are left at the institution to reinforce lessons learned and help new staff to catch up with their moreexperienced colleagues. The ability of member wildlife centres to train their own staff will provide sustainability and reduce dependence on PASA.

In addition to improving welfare, this training programme also has a positive influence on conservation. It increases the overall effectiveness and reputation of the sanctuaries, meaning governments are more likely to send to them primates that local law-enforcement agencies have confiscated from wildlife traffickers. Having suitable homes for confiscated apes and monkeys increases the government's capacity and motivation to arrest traffickers, thereby preventing the removal of additional animals from the wild.

\section{Veterinary Supplies Program}

Many of PASA's member wildlife centres have an urgent need for medical supplies that are difficult or impossible to source in Africa. PASA receives donations of supplies from non-profit organizations and zoos, and uses its network of collaborators who frequently travel between the United States and Africa to identify people who can bring the supplies when they travel to wildlife centres. PASA also seeks financial donations to facilitate the purchase of greatly needed medical supplies. Travelling with certain drugs into some countries requires additional considerations, such as a 
letter of permission from a government veterinary authority; the specific requirements depend on the country. Lincoln Park Zoo in Chicago, IL, USA, very generously solicits donations of veterinary supplies and stores them until people who will bring the materials to Africa are found. PASA is continuously seeking more zoos and other organizations that can provide veterinary supplies.

One important focus for PASA's Veterinary Supplies Program is acquiring contraceptives. PASA-member sanctuaries only voluntarily permit animals to reproduce if breeding is part of a currently active release programme in accordance with the International Union for Conservation of Nature (IUCN) guidelines for reintroductions (Baker, 2002; Beck et al., 2007), and where reproduction does not compromise the resources of the sanctuary, or negatively impact the health and welfare of the other animals also living there. Reversible contraception is used, wherever possible, on primates that may be reintroduced. Decisions about contraception are made by each sanctuary's veterinary staff based on the animal's age, sex and potential for reintroduction.

\section{Emergency support programme}

PASA provides crisis grants to its member wildlife centres to help them recover from emergencies that are beyond their control, such as fires, collapsed buildings and the recent Ebola outbreak. PASA aims to address these issues as quickly as possible, to ensure that the apes and monkeys under the care of PASA-member sanctuaries do not suffer as a result of unforeseen circumstances. In 2016, heavy rains in East Africa caused flooding at Sweetwaters Chimpanzee Sanctuary in Kenya and Ngamba Island Chimpanzee Sanctuary in Uganda. PASA gave a grant to Sweetwaters to rebuild an electric fence that keeps the Chimpanzees Pan troglodytes safely in the enclosure. A grant was also given to help Ngamba Island to build a retaining wall to protect the sanctuary facilities from the flood and reduce the impact of future floods.

\section{CONSERVATION-EDUCATION ACTIVITIES}

In addition to advocating for and supporting its member organizations, PASA collaborates with them on large-scale conservation-education initiatives, which are made possible with funding and technical support from zoos in North America and Europe.

\section{Cameroon Conservation Education Program}

In 2015, PASA and its member organizations in Cameroon launched the Cameroon Conservation Education Program with the goals of (1) determining the most effective approach to inspiring Cameroonian children to protect their country's wildlife and other natural resources, and (2) teaching tens of thousands of schoolchildren in Cameroon the value of protecting animals and their habitats. This is expected to engender a long-term nationwide shift in the population's attitudes and behaviour regarding conservation, resulting in an increase in the number and size of protected areas, stronger legal protections for natural habitat and an increase in the abundance of threatened species in Cameroon. In July 2015, a community-engagement workshop was convened in Cameroon. A director and two community-engagement programme staff from each of the three sanctuaries located in the country attended the workshop (PASA, 2016).

A very successful pilot study was held in Cameroon in 2016 with several thousand students. Highlights of the evaluation results included an increase from 57\% to $98 \%$ in students who understood that Chimpanzees should not be eaten as bushmeat, and an increase from $34 \%$ to $68 \%$ of students who knew to contact the police if they see a Chimpanzee in a neighbour's house. Sanaga-Yong Chimpanzee Rescue and Ape Action Africa are expanding this 


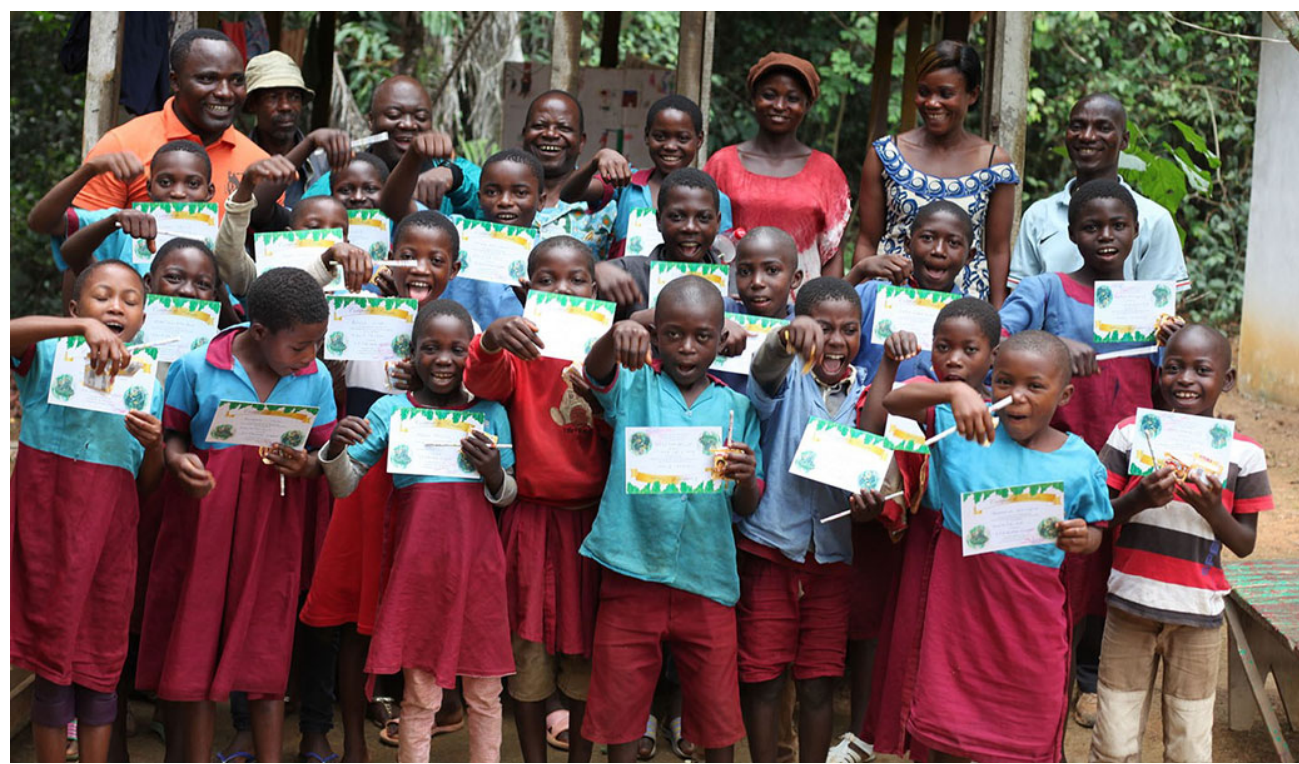

Plate 2. Children display their certificates of achievement upon completing the Cameroon Conservation Education Program. Sanaga-Yong Chimpanzee Rescue, 2017.

education programme to reach thousands more Cameroonian youth in 2017 and are obtaining similar results (Plate 2).

\section{Edutainment Films Program}

The Edutainment Films Program is a pioneering initiative in Africa to distribute high-quality, engaging films with conservation messaging that were created specifically for African audiences. The flagship movies of the programme were produced by the non-profit Stichting Nature for Kids (Bussum, The Netherlands), which makes excellent, entertaining films with messages about environmental conservation. In a pilot programme, hundreds of thousands of people in Cameroon saw the films on national television and on the national train system. Following this tremendous success, PASA is expanding this Film Program to include ten African countries. The ways in which the films are distributed in each country depends on the resources of the PASAmember organizations in the country; for example, some have connections with national television networks, others have tens of thousands of visitors to their wildlife centres and some conduct education programmes that reach thousands of students every year.

\section{Worldwide bushmeat awareness campaign}

Few people are aware of the bushmeat crisis, its inherent cruelty, or that it is now considered the greatest threat to the future of African primates. Bushmeat originates from wild animals that are hunted, captured and killed specifically for their meat. Studies have shown that there is a chain of actors along the commodity chain of this illegal trade, and it is difficult to prevent such hunting (see Tagg et al., 2018). Effecting behaviour change is likely to be the best way to reduce the illegal trade in bushmeat. In August 2016, PASA launched a campaign to educate people worldwide and motivate them to act in an online movement against the bushmeat trade. A cornerstone of the campaign is a petition 
which provides an easy way for people to become involved. Signatories receive a series of e-mails that inform and engage them. The strong emotional appeal of the issue, including the baby Chimpanzees and gorillas orphaned by the trade, enables the campaign to be shared widely via social media and influence public opinion. Complementing this global campaign, PASA-member sanctuaries conduct education programmes and community-based projects near critical wildlife habitat to reduce the illicit hunting, trade and consumption of bushmeat.

\section{NEW CONSERVATION ACTIVITIES}

At the time of writing, PASA is working to launch new conservation projects, some of which are briefly described below.

\section{Ending wildlife trafficking: educating law-enforcement programme}

Illegal trafficking, driven by demand for exotic pets and live props in the entertainment industry, is a significant threat to ape conservation. Between 2005 and 2011, there were an estimated 22218 cases of ape trafficking. Of these, only 27 arrests were made, $25 \%$ of which were never prosecuted. This indicates that law enforcement has been almost non-existent (Stiles et al., 2013: page 8). A major reason for this is that many enforcement officials receive inadequate training, or no training at all, in the prevention of wildlife crime. PASA aims to address this by creating educational media that can be easily distributed to, and understood by, enforcement officials across Africa and the Middle East. The media will include printed materials, such as posters and leaflets, as well as electronic files and a smartphone app. In the short term, this endeavour will improve animal welfare, because live confiscated animals will be sent to accredited sanctuaries rather than being sold to disreputable entertainment industries or to individuals as pets. In the long term, increased enforcement will make wildlife trafficking a much more difficult and less-profitable crime, and fewer apes will be removed from the wild.

\section{Sustainable communities programme}

Almost all PASA-member organizations manage community-based projects near vital primate habitat, where local people illegally hunt wildlife and destroy habitat. PASA is connecting its members with organizations that specialize in communitydevelopment projects in Africa and facilitate new partnerships. For example, PASA has linked Ngamba Island Chimpanzee Sanctuary, which uses radio dramas to educate the public about the importance of Chimpanzees in the wild, to a non-profit organization that specializes in using radio to produce social change. The main aim is to improve the effectiveness of African community development programmes in reducing threats to wildlife.

The combination of PASA's global network, and the local expertise and connections of its member organizations, uniquely positions the Alliance to produce lasting changes to protect Africa's great apes and monkeys.

\section{GREAT APE RESEARCH AT PASA- MEMBER SANCTUARIES}

In addition to playing an essential role in primate welfare and conservation, almost all PASA-member wildlife centres host researchers from universities, zoos and other institutions worldwide. The researchers arrange this by contacting the sanctuaries directly. Cooperation between PASA-member institutions and academics has greatly increased knowledge about the behaviour and physiology of great apes (and other African primates), and has enabled a better understanding of the evolution of humans.

Research comparing human children and the apes at PASA-member sanctuaries has provided support for the 'cultural intelligence hypothesis'; that is, the idea that human cognition is unique not because we are generally more intelligent than other 
species, but rather because we specifically excel at skills needed for cultural learning and transmission (Herrmann et al., 2007; Wobber et al., 2014).

Work in sanctuary populations has also shown that Chimpanzees frequently collaborate to gain mutual benefits (Melis et al., 2006a,b, 2009) or simply to assist a partner (Warneken et al., 2007; Melis et al., 2011). However, unlike humans, Chimpanzees generally show a preference for working alone unless having a partner is obligatory for success (Melis et al., 2006a; Bullinger et al., 2011; Rekers et al., 2011).

Moreover, research carried out at PASAmember sanctuaries has helped to elucidate many behavioural (Hare et al., 2007; Wobber, Wrangham \& Hare, 2010; Woods \& Hare, 2011; Rosati \& Hare, 2012a,b, 2013; Rosati, 2015) and hormonal (Wobber, Hare et al., 2010; Wobber et al., 2013) differences between Chimpanzees and Bonobos Pan paniscus. This is especially important because while most comparisons between humans and apes focus on Chimpanzees, we have an equally close evolutionary relationship with Bonobos and could have much to gain by an increased understanding of them (Groves, 2018).

Lastly, research in sanctuaries has revealed new insights into how humans have evolved certain traits that differ from those of other primates, including a large brain and more frequent reproduction. One proposed explanation is Richard Wrangham's influential 'cooking hypothesis', arguing that an early adoption of a high-energy cooked diet played a critical role in the ability of our species to grow such large brains (Wrangham, 2009). Research in PASA sanctuaries has revealed that Chimpanzees possess some foundational cognitive and behavioural skills needed to engage in cooking behaviours, providing important behavioural tests of this hypothesis (Wobber et al., 2008; Warneken \& Rosati, 2015).

\section{CONCLUSION}

PASA and its member sanctuaries work tirelessly to improve great ape welfare and conservation, and also enable researchers to further illuminate our evolutionary origins through comparisons with our closest living relatives.

PASA is enthusiastic to continue its long-standing collaborations with zoos worldwide and develop new partnerships. PASA can provide zoos with photographs, stories and other content that can be used to inform visitors about the conservation work being supported. Additionally, the Alliance's website has infographics (https:// www.pasaprimates.org/infographics-poste rs), and other information about the threats to African apes and the work being done to protect them, which zoos can use in their marketing and interpretive materials. PASA can connect zoo personnel to sanctuaries where they may conduct research, form partnerships on conservation projects, volunteer or collaborate in other ways.

PASA unites its member organizations in collaborative initiatives conducted at a much larger scale than would be feasible if they were acting alone. Without assistance from zoos around the world, however, much of PASA's work would not be possible. Zoos regularly provide funding and technical support that allow PASA to continue to expand its efforts to secure a future for the African great apes and their habitats. Zoos interested in supporting or working with PASA are always welcome to send an inquiry. For more information about PASA's programmes or opportunities to conduct research at a PASA-member sanctuary, please visit www.pasaprimates.org.

\section{ACKNOWLEDGEMENTS}

We thank Brian Hare for providing us with information on noteworthy research projects conducted at PASA-member sanctuaries and Erica Peth for constructive feedback.

\section{REFERENCES}

BAKER, L. R. (2002): IUCN/SSC Re-introduction Specialist Group: guidelines for nonhuman primate reintroductions. Re-introduction News No. 21: 29-57.

Beck, B., Rodrigues, M. \& Unwin, S. (2007): Best practice guidelines for the re-introduction of great 
apes. Gland, Switzerland: SSC Primate Specialist Group of the World Conservation Union.

Bullinger, A. F., Melis, A. P. \& Tomasello, M. (2011): Chimpanzees, Pan troglodytes, prefer individual over collaborative strategies towards goals. Animal Behaviour 82: 1135-1141.

Ferrie, G. M., Farmer, K. H., Kuhar, C. W., Grand, A. P., Sherman, J. \& Bettinger, T. L. (2014): The social, economic, and environmental contributions of Pan African Sanctuary Alliance primate sanctuaries in Africa. Biodiversity and Conservation 23: 187-201.

Groves, C. P. (2018): The latest thinking about the taxonomy of great apes. International Zoo Yearbook 52: $16-24$.

Hare, B., Melis, A. P., Woods, V., Hastings, S. \& Wrangham, R. (2007): Tolerance allows bonobos to outperform chimpanzees on a cooperative task. Current Biology 17: 619-623.

Herrmann, E., Call, J., Hernández-Lloreda, M. V., Hare, B. \& Tomasello, M. (2007): Humans have evolved specialized skills of social cognition: the cultural intelligence hypothesis. Science 317: 1360-1366.

Melis, A. P., Hare, B. \& Tomasello, M. (2006a): Chimpanzees recruit the best collaborators. Science 311: 1297-1300.

Melis, A. P., Hare, B. \& Tomasello, M. (2006b): Engineering cooperation in chimpanzees: tolerance constraints on cooperation. Animal Behaviour 72: 275286.

Melis, A. P., Hare, B. \& Tomasello, M. (2009): Chimpanzees coordinate in a negotiation game. Evolution and Human Behavior 30: 381-392.

Melis, A. P., Warneken, F., Jensen, K., Schneider, A. C., Call, J. \& Tomasello, M. (2011): Chimpanzees help conspecifics obtain food and non-food items. Proceedings of the Royal Society of London B: Biological Sciences 278: 1405-1413.

PASA (2016): Community engagement workshop in Cameroon: workshop report. Portland, OR: Pan African Sanctuary Alliance. Available at https://www.pasa primates.org/reports-manuals

PASA (2017): Pan African Sanctuary Alliance Strategic Development Conference, Chingola, Zambia, September 6 to 9, 2017: summary report. Portland, OR: Pan African Sanctuary Alliance. Available at https://www.pasaprimates.org/wp/wp-content/uploads/ 2016/04/PASA2017_SDCReport.pdf

Rekers, Y., Haun, D. B. \& Tomasello, M. (2011): Children, but not chimpanzees, prefer to collaborate. Current Biology 21: 1756-1758.

Rosati, A. G. (2015): Context influences spatial frames of reference in bonobos (Pan paniscus). Behaviour 152: 375-406.

Rosati, A. G. \& Hare, B. (2012a): Chimpanzees and bonobos exhibit divergent spatial memory development. Developmental Science 15: 840-853.
Rosati, A. G. \& Hare, B. (2012b): Decision making across social contexts: competition increases preferences for risk in chimpanzees and bonobos. Animal Behaviour 84: 869-879.

Rosati, A. G. \& Hare, B. (2013): Chimpanzees and bonobos exhibit emotional responses to decision outcomes. PLOS ONE 8(5): Art. e63058.

Stiles, D., Redmond, I., Cress, D., Nellemann, C. \& Formo, R. K. (Eds) (2013): Stolen apes - the illicit trade in chimpanzees, gorillas, bonobos and orangutans. A rapid response assessment. Nairobi: United Nations Environment Programme, GRID-Arendal.

TagG, N., Maddison, N., Dupain, J., McGilchrist, L., Mouamfon, M., McCabe, G., NGo Badjeck, M. M., Tchouankep, M., Mbohli, D., Epanda, M. A., Ransom, C. \& FA, J. E. (2018): A zoo-led study of the great ape bushmeat commodity chain in Cameroon. International Zoo Yearbook 52: 182-193.

Warneken, F. \& Rosati, A. G. (2015): Cognitive capacities for cooking in chimpanzees. Proceedings of the Royal Society of London B: Biological Sciences 282: Art. 20150229.

Warneken, F., Hare, B., Melis, A. P., Hanus, D. \& Tomasello, M. (2007): Spontaneous altruism by chimpanzees and young children. PLoS Biology 5(7): Art. e184.

Wobber, V., Hare, B. \& Wrangham, R. (2008): Great apes prefer cooked food. Journal of Human Evolution 55: $340-348$.

Wobber, V., Hare, B., Мавото, J., Lipson, S., Wrangham, R. \& Ellison, P. T. (2010): Differential changes in steroid hormones before competition in bonobos and chimpanzees. Proceedings of the National Academy of Sciences 107: 12457-12462.

Wobber, V., Wrangham, R. \& Hare, B. (2010): Bonobos exhibit delayed development of social behavior and cognition relative to chimpanzees. Current Biology 20: $226-230$.

Wobber, V., Hare, B., Lipson, S., Wrangham, R. \& Ellison, P. (2013): Different ontogenetic patterns of testosterone production reflect divergent male reproductive strategies in chimpanzees and bonobos. Physiology \& Behavior 116: 44-53.

Wobber, V., Herrmann, E., Hare, B., Wrangham, R. \& Tomasello, M. (2014): Differences in the early cognitive development of children and great apes. Developmental Psychobiology 56: 547-573.

Woods, V. \& Hare, B. (2011): Bonobo but not chimpanzee infants use socio-sexual contact with peers. Primates 52: 111-116.

Wrangham, R. (2009): Catching fire: how cooking made us human. New York, NY: Basic Books.

Manuscript submitted 25 May 2017; revised 20 November 2017; accepted 28 November 2017 